EGU2020-5910

https://doi.org/10.5194/egusphere-egu2020-5910

EGU General Assembly 2020

(c) Author(s) 2021. This work is distributed under

the Creative Commons Attribution 4.0 License.

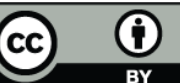

\title{
Semi-automatic road damage detection in landslide areas using UAV-based 3D models
}

\author{
Nicoletta Nappo ${ }^{1,2}$, Olga Mavrouli ${ }^{2}$, Cees van Westen ${ }^{2}$, Roberto Gambillara ${ }^{1}$, and Alessandro \\ Maria Michetti \\ ${ }^{1}$ University of Insubria, Department of Science and High Technology, Italy (nnappo@studenti.uninsubria.it) \\ ${ }^{2}$ University of Twente, Faculty of Geo-Information Science and Earth Observation (ITC), The Netherlands
}

The efficiency of linear infrastructure influences heavily the social and economic development of a territory; hence the assessment of pavement damage is of major interest for local authorities when planning road maintenance in landslide affected areas to ensure the safety of its users. Ground movements related to landslides, subsidence and earthquakes are common causes of pavement deterioration, other than usual traffic stress conditions. Major issues for the assessment of landslide impacts on transportation routes remain the quantitative and objective description of the typology and extent of pavement damage, and its classification, with the aim to correlate the damage with the nature and intensity of the causing phenomena. This work investigates the use of three-dimensional models reconstructed from UAV based digital photogrammetry, as a rapid and less laborious alternative to the traditional field surveys, for assessing the damage induced by slow-moving landslides interacting with linear infrastructure. A semi-automatic procedure is proposed to rapidly detect and quantitatively describe the damage on asphalt-paved roads affected by slow-moving landslides. The methodology includes the processing of the 3D points cloud models using edge detection algorithms and roughness estimations to detect pavement anomalies. Damage assessment using the proposed methodology allows to i) automatically extract the geometric features of road damage, ii) measure objectively fractures and/or deformations of the road pavement and iii) create a damage database using geolocation data. The procedure is applied to road tracks located within slow-moving landslides and tested using RGB images taken from a Phantom 4 drone flight at $30 \mathrm{~m}$ and $10 \mathrm{~m}$ altitudes from the road surface and field measurements. The proposed methodology for semi-automatic road damage detection can contribute to the improvement of landslide risk analysis and mitigation for road networks affected by ground movements. 